\title{
Microstructure and Quasi-Static Mechanical Behavior of Cryoforged AA2519 Alloy
}

\author{
Amin Azimi ${ }^{1}$, Gbadebo Moses Owolabi ${ }^{1}$, Hamid Fallahdoost ${ }^{2}$, Nikhil Kumar ${ }^{1}$, Horace Whitworth ${ }^{1}$ \\ ${ }^{1}$ Department of Mechanical Engineering, Howard University, Washington DC, USA \\ ${ }^{2}$ Department of Mechanical Engineering, Materials Science and Engineering Program, Binghamton University (SUNY), \\ Binghamton, NY, USA \\ Email:amin.azimi@bison.howard.edu,aminazimi.kntu@gmail.com
}

How to cite this paper: Azimi, A., Owolabi, G.M., Fallahdoost, H., Kumar, N. and Whitworth, H. (2019) Microstructure and Quasi-Static Mechanical Behavior of Cryoforged AA2519 Alloy. Materials Sciences and Applications, 10, 137-149.

https://doi.org/10.4236/msa.2019.102011

Received: January 9, 2019

Accepted: January 27, 2019

Published: January 30, 2019

Copyright $\odot 2019$ by author(s) and Scientific Research Publishing Inc. This work is licensed under the Creative Commons Attribution International License (CC BY 4.0).

http://creativecommons.org/licenses/by/4.0/

\begin{abstract}
In this study, AA2519 alloy was initially processed by multi axial forging (MAF) at room and cryogenic temperatures. Subsequently, the microstructure and the mechanical behavior of the processed samples under quasi-static loading were investigated to determine the influence of cryogenic forging on alloys' subgrains dimensions, grain boundaries interactions, strength, ductility and toughness. In addition, the failure mechanisms at the tensile rupture surfaces were characterized using scanning electron microscope (SEM). The results show significant improvements in the strength, ductility and toughness of the alloy as a result of the cryogenic MAF process. The formation of nanoscale crystallite microstructure, heavily deformed grains with high density of grain boundaries and second phase breakage to finer particles were characterized as the main reasons for the increase in the mechanical properties of the cryogenic forged samples. The cryogenic processing of the alloy resulted in the formation of an ultrafine grained material with tensile strength and toughness that are $\sim 41 \%$ and $\sim 80 \%$ higher respectively after 2 cycles MAF when compared with the materials processed at ambient temperature. The fractography analysis on the tested materials shows a substantial ductility improvement in the cryoforged (CF) samples when compared to the room temperature forged (RTF) samples which is in alignment with their stress-strain profiles. However, extended forging at higher cycles than 2 cycles led only to increase in strength at the expense of ductility for both the CF and RTF samples.
\end{abstract}

\section{Keywords}

AA2519 Aluminum Alloy, Cryogenic Forging, Quasi-Static Mechanical Behavior, Microstructure Investigation, Fractography Analysis 


\section{Introduction}

Severe Plastic Deformation (SPD) may be described as a metal forming process in which an ultra-large plastic strain is applied into a bulk metal leading to a gradual formation of nano/ultrafine grained structures [1]. SPD has emerged as a promising method for the development of bulk ultrafine grained (UFG) and nanostructured materials over the last two decades [2]. Accumulation of dislocations in cell walls followed by formation of small and large angle grain boundaries within the original cell satisfies the required conditions for the grain size refinement during SPD process [3]. Low-angle grain boundaries are formed in regions of high dislocation densities and then transformed into high-angle grain boundaries in high accumulated dislocation areas by extending the process. This results in a reduction of the grain size via the SPD process [4]. Several SPD methods such as Equal Channel Angular Pressing (ECAP) [5], Accumulative Roll-Bonding (ARB) [6], High Pressure Torsion (HPT) [7] and Multi Axial Forging (MAF) [8] have been developed. MAF is a relatively simple SPD process that consists of repeated compression in three orthogonal directions associated with a change in the axis to $90^{\circ}$ in every pass leading to the attainment of a uniform texture with low aspect ratio grains within the material. Not only does it have the potential for scaling up of the processed products, but it also preserves the original shape with least distortion even after several cycles, which is ideal for industrial applications [9].

Despite of the positive SPD impacts on microstructural modifications, the rate of defect storage and structural refinement decreases significantly with increasing strain due to dynamic recovery and recrystallization of grains during the plastic deformation [10]. In this regard, cryogenic SPD has been established as a much more effective approach while dynamic recovery is suppressed at a liquid nitrogen temperature and accordingly facilitates the formation of UFG structures. The complete suppression of dynamic recovery and recrystallization during the cryogenic plastic deformation preserves high density dislocations and other defects developed during the deformation, thus requiring less plastic deformation for generating UFG structure [11] [12].

UFG materials are structurally identified by a large volume fraction of grain boundaries, which significantly affect their physical and mechanical characteristics such that mechanical strength of metals can be substantially improved by this grain size refinement into the sub-micrometer range [13] [14]. Particularly, UFG aluminum alloys are seeing as a lightweight substitute to the conventional heavy materials used in the automotive and the aerospace industries [15]. The small grain size with high fraction of atoms ascribed to the grain boundaries results in the increase in the mechanical strength of the materials without losing the toughness, which distinguishes this method from other strengthening methods such as heat treatment [16]. This distinction between UFG and coarse-grained polycrystalline materials has been very well explained by the Hall-Petch relationship and corresponds to different deformation mechanisms [17]. For in- 
stance, predominant mechanisms of plastic deformation for coarse grained metallic materials are intragrain dislocation slip and twinning. On the other hand, since activation energy of plastic deformation is close to the activation energy of grain boundary diffusion, the diffusion-controlled mechanisms such as grain boundary sliding and grain rotation can be efficiently activated in UFG materials due to large volume fraction of grain boundaries which are in a nonequilibrium state [18]. Some cryogenic SPD processes on various metals were studied by recent researches [12] [19] [20] [21] showing a considerable mechanical improvement.

To the best of the authors' knowledge, no data is available in literature on the quasi-static mechanical behavior of the UFG AA2519 processed by MAF at cryogenic temperature. Thus, the main objective of this paper is to investigate the microstructure and mechanical properties of the cryoforged (CF) AA2519 using the room temperature forged (RTF) alloy as the reference material. In addition, the microstructure of the fractured surface was characterized to provide an insight into the failure mechanisms in the tested materials. The number of forging cycles is also considered as a variable to determine the effect of further processing cycle on the materials properties.

\section{Materials and Methods}

A commercial AA2519 alloy was used in this study with the chemical compositions summarized in Table 1 . The samples were first solution treated at a temperature $500^{\circ} \mathrm{C}$ for $10 \mathrm{hrs}$ in a controlled atmosphere of argon, and then quenched in water at ambient temperature. The MAF process was carried out in friction screw forging machine at a strain rate of $10 \mathrm{~s}^{-1}$. Axial compression at an equivalent true strain of $(\Delta \mathcal{E})=\ln (1 / 1.18)=-0.165$ was successively induced for one forging pass. Thus, the cumulative strain in one cycle was calculated as $\left(\Sigma \Delta \varepsilon_{\mathrm{n}=1}\right)=\left|\Delta \varepsilon_{1}+\Delta \varepsilon_{2}+\Delta \varepsilon_{3}\right|=-0.495$. The extrusion direction of the starting sample was used as the first forging axis. To reach the cryogenic temperature, the samples were submerged in liquid nitrogen for 15 mins. The samples were then repeatedly forged by changing the axis through $90^{\circ}$ in order to maintain the dimensional ratio of 1.18:1.11:1.0 at the end of the process. Prior to each pass, quenching in liquid nitrogen for about 5 to $10 \mathrm{~min}$ was conducted to keep the samples in a thermal equilibrium with the liquid nitrogen. Eventually, The AA2519 samples were subjected to cumulative strains of $-0.99,-1.98$ and -2.97 for 2 cycles ( 6 passes), 4 cycles (12 passes) and 6 cycles (18 passes), respectively. The structural changes of the alloys caused by cryogenic forging was evaluated by means of X-ray diffraction measurement (XRD) using a Philips diffractometer at a voltage and electrical current of $40 \mathrm{kV}$ with $\mathrm{Cu}-\mathrm{Ka}$ radiation $(\lambda=0.15406 \mathrm{~nm})$.

Table 1. Chemical composition of the AA2519 aluminum alloy.

\begin{tabular}{ccccccccccc}
\hline Elements & $\mathrm{Cu}$ & $\mathrm{Fe}$ & $\mathrm{Mg}$ & $\mathrm{Mn}$ & $\mathrm{Si}$ & $\mathrm{Ti}$ & $\mathrm{V}$ & $\mathrm{Zn}$ & $\mathrm{Zr}$ & $\mathrm{Al}$ \\
\hline wt\% & $5.3-6.4$ & 0.3 & $0.05-0.4$ & $0.1-0.5$ & 0.25 & $0.02-0.1$ & $0.05-0.15$ & 0.1 & $0.1-0.25$ & Bal.
\end{tabular}


The XRD patterns were collected over $2 \theta$ range of $20^{\circ}-100^{\circ}$ with a step size of $0.031^{\circ}$. The subgrains structure and grain boundaries interaction in the UFG samples were studied using a transmission electron microscope (TEM; Model: FEI Technai) with a voltage of $200 \mathrm{kV}$ and also using a Zeiss optical microscope. The fractured surfaces were investigated using SEM to observe the microscopic features of failure in each case. Microhardness measurements were also carried out on the central cross-section surface using a Vickers indenter at a load of $50 \mathrm{~g}$ and a dwell time of $10 \mathrm{~s}$. Tensile tests at a strain rate of $1 \mathrm{~mm} / \mathrm{min}$ were conducted using a UTS-type machine (S-series H25k-S Model) at an ambient temperature based on the ASTM: E8M standard.

\section{Results and Discussion}

\subsection{Microstructure Characterization}

XRD scattering pattern results are depicted in Figure 1 (a) representing the diffraction spectra of the RTF and the CF samples at 6 cycles. The magnified Al (111) peaks are also illustrated to accurately predict the microstructural changes. The existence of dispersed $\mathrm{Al}_{2} \mathrm{Cu}$ second phase particles throughout the $\mathrm{Al}$ matrix can be confirmed by peaks $2 \theta$ angles which matched with $\mathrm{Al}$ and $\mathrm{Al}_{2} \mathrm{Cu}$ phases' standard locations. The basic reinforcing phases are $\mathrm{Al}_{2} \mathrm{Cu}$ in this alloy.

According to Figure 1(a), a comparison of the major $\mathrm{Al}$ (111) peaks in the magnified XRD patterns between the CF and RTF AA2519 samples shows that the $\mathrm{Al}$ peaks' intensities were decreased and became broadened and shifted to smaller degrees through the cryoforging process which is a strong indicator of the alteration of the lattice parameters of the $\mathrm{Al}$ due to high internal lattice strain

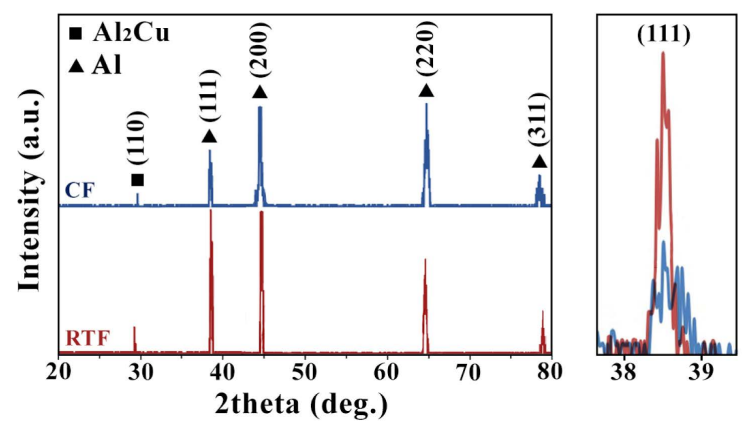

(a)

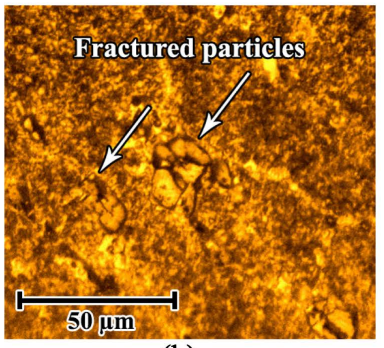

(b)

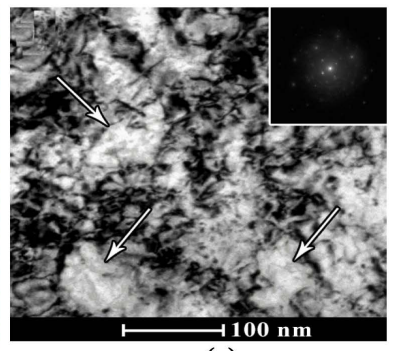

(c)

Figure 1. (a) X-ray diffraction pattern of the RTF and CF; (b) Optical and (c) TEM micrographs of CF processed AA2519. 
and defects [22] [23]. The high crystallite refinement and lattice strain increment in the $\mathrm{Al}$ matrix occurred as the results of more effective SPD during the cryogenic process. In this case, the dynamic recovery is systematically stopped at the liquid nitrogen temperature which leads to diminishing dislocation mobility and allowing the accumulation of dislocation density to achieve a higher steady state level. Similar peak broadening and intensity reduction in UFG 6061 aluminum alloy during dissimilar channel angular pressing was observed by Tan et al. [24].

The XRD analysis suggested that the intensity of the $\mathrm{Al}_{2} \mathrm{Cu}$ diffraction peaks in a RTF alloy was a little stronger than that in a CF alloy, indicating that the amount of $\mathrm{Al}_{2} \mathrm{Cu}$ precipitates after ambient process had increased. Higher thermal energy and increase of local temperature during forging at a room temperature may supply the driving force for the reaction between $\mathrm{Al}$ and $\mathrm{Cu}$ to form $\mathrm{Al}_{2} \mathrm{Cu}$. Furthermore, the broadened $\mathrm{Al}_{2} \mathrm{Cu}$ peaks with lower intensity in the $\mathrm{CF}$ samples are also an indication of the second phase breakage to finer particles as a result of the induced high plastic strain through the forging process at cryogenic temperature. This process exerts a strong plastic deformation leading to the generation of more shear intense stress followed by the breaking down of the second phase particles. This $\mathrm{Al}_{2} \mathrm{Cu}$ particles breakage can be accompanied by redistribution through the $\mathrm{Al}$ matrix, which assured a more homogeneous microstructure and stronger mechanical strength. The fragmented $\mathrm{Al}_{2} \mathrm{Cu}$ particles in $\mathrm{Al}$ matrix after cryogenic deformation in the CF samples shown in Figure 1(b) confirms the data obtained from the XRD analysis. Adamczyk-Cieslak et al. [25] also observed the breaking and rearrangement of the precipitates in $2 \mathrm{xxx}$ aluminum alloys as a result of SPD.

The microstructure of grains/subgrains of the 6 cycles CF AA2519 was investigated through transmission electron micrographs in Figure $1(\mathrm{c})$ to realize the materials characteristics which were not possible to resolve via optical microscopy. As clearly shown in Figure 1(c), the grains were plastically deformed and were surrounded by high density of dislocations.

The severely deformed cells marked with arrows in Figure 1(c) are indication of the grains/subgrains size which falls within a nano-metric scale. The generation of this distorted nanoscale subgrains and the development of nanoscale deformation twins at locally accumulated grain boundaries show that cryogenic forging influences the microstructure of the material. This grain refinement and grain boundaries accumulation can be expected as a significant microstructural evolution while intense plastic strain corresponds with the restriction of dynamic recovery and recrystallization mechanisms. Atomic mismatch in the accumulated dislocation regions leads to the generation of a high plastic strain and deformations bands. Further strain makes the dislocation walls and tangles to transform into sub-boundaries with small misorientation in the original grains separating the individual cells or subgrains [26]. Chen et al. [21] studied equal-channel deformation of an Al-Mg alloy at cryogenic temperatures and reported such high-density dislocations distorted grains to a refining grain size. However, increase in strain in the RTF processing no longer results in grain re- 
finement to nano/ultrafine size since the dislocation multiplication rate in the RTF processing is balanced by the annihilation rate. In addition, $\mathrm{Cu}$ solutes in the AA2519 alloy increase the stacking fault energy which may activate cross-slip mechanism. This mechanism suppresses dislocation climb and the rearrangement of lattice dislocations resulting in the formation of high strains and intense refinement in cell structure [27].

\subsection{Mechanical Behavior}

The stress-strain curves for the quasi-static tensile test results are shown in Figure 2. This section provides an overview of several aspects of the mechanical behavior of the RTF and CF processed materials in which the number of the forging cycles $(2,4$ and 6$)$ was considered as a variable parameter. In addition, the ultimate tensile strength (UTS), the percentage elongation and the toughness graphs for the tested samples are presented in Figure 3 as a function of the forging cycles. To provide more quantitative data, the mechanical properties obtained from these curves along with the hardness measurement results from the Vickers indentation tests are also summarized in Table 2.

The stress-strain curves in Figure 2(a) and Figure 2(b) show that further forging process to the next cycles resulted in a significant increase in the UTS values for both CF and RTF samples. The UTS values increase by $33 \%$ and $26 \%$ when processed from 2 to 6 cycles for the RTF and the CF samples, respectively. This can be due to further crystallite size refinement at higher cycles of the SPD

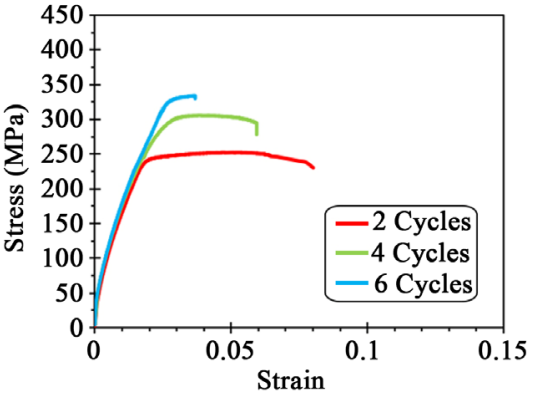

(a)

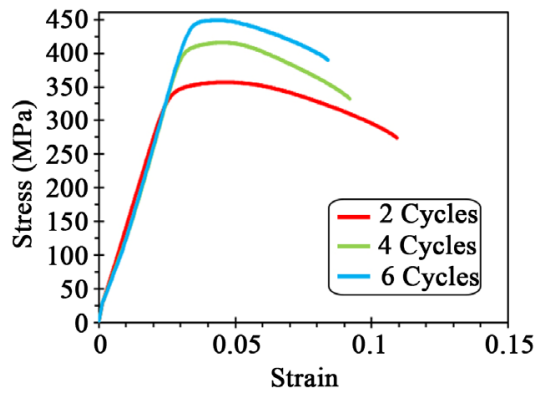

(b)

Figure 2. Stress-Strain curves of the (a) RTF and (b) CF samples.

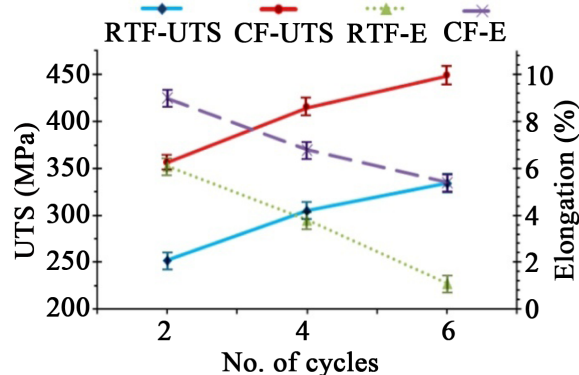

(a)

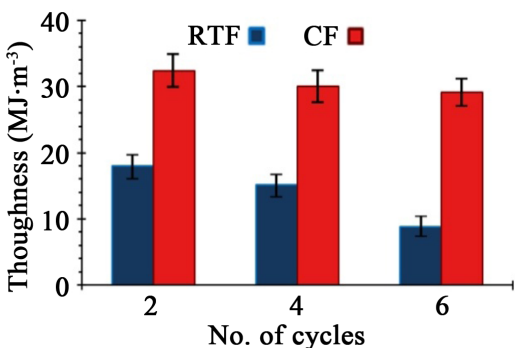

(b)

Figure 3. (a) UTS; elongation and (b) Toughness of the RTF and CF samples vs. number of forging cycles. 
Table 2. The derived mechanical properties from stress-strain graphs plus hardness.

\begin{tabular}{cccccc}
\hline Materials & No. of Cycles & $\begin{array}{c}\text { Ultimate Tensile } \\
\text { Strength }(\mathrm{MPa})\end{array}$ & $\begin{array}{c}\text { Elongation } \\
(\%)\end{array}$ & $\begin{array}{c}\text { Toughness } \\
\left(\mathrm{MJ} \cdot \mathrm{m}^{-3}\right)\end{array}$ & $\begin{array}{c}\text { Hardness } \\
(\mathrm{Hv})\end{array}$ \\
\hline \multirow{2}{*}{ RTF-AA2519 } & 2 & 252 & 6.1 & 18.03 & 98 \\
& 4 & 305 & 3.8 & 15.09 & 130 \\
& 6 & 334 & 1.1 & 8.77 & 149 \\
CF-AA2519 & 2 & 356 & 9.0 & 32.45 & 165 \\
& 4 & 415 & 6.8 & 30.06 & 198 \\
& 6 & 449 & 5.4 & 29.14 & 221 \\
\hline
\end{tabular}

process. In fact, high volume of accumulated grain boundaries in the deformed materials acts as barriers for the movement of dislocations thereby preventing further deformation [28]. However, thermomechanical balance in kinetics of grains recrystallization and refinement led to a decrease in the strength enhancement from 4 to 6 cycles in comparison to processing from 2 to 4 cycles.

As expected, Table 2 indicates a similar increasing trend for the hardness measurements with UTS. The correlation between hardness values and tensile strengths are often linear even though it strongly depends on the ability of the metals to strain harden especially in UFG materials which normally present a low level of strain hardening [29].

Although, limited amount of changes were obtained by performing the forging process at higher cycles, the tensile profiles show much more significant influences on the mechanical properties of the CF materials than that of the RTF samples. The UTS values indicate that cryogenic processing creates materials with $41 \%$ higher strength after 2 cycles of MAF when compared with the samples processed at ambient temperature. In cryoforging, the strain-hardening is preserved up to the extent to which forging is done. This signifies that neither dislocation recovery nor recrystallization occurs during the entire SPD process whereas dynamic recovery and subsequent softening are inevitable in the materials under conventional forging. In other words, climb of dislocations and cross slip are extensively inhibited within the cryogenic process thereby accumulating high dislocation density which is not the case for ambient forging. Consequently, nanocrystalline/UFG microstructure with bi-modal grains is developed in the CF alloy resulting in high mechanical strength which is in consistence with the Hall-Petch strengthening mechanism. Similar increase in the UTS from 315 to $522 \mathrm{MPa}$ was reported by Lee et al. [19] as a result of cryorolling of 5083 aluminum alloy while they observed $490 \mathrm{MPa}$ for UTS after room temperature rolling with the same reduction. Meanwhile, the positive effect of the fractured second phases on the strength of CF samples should not be overlooked. They followed Orowan mechanism to hinder dislocation movements [30].

It is widely known that the improvement of mechanical strength in SPD processed materials is followed by ductility reduction. According to Figure 3(a), the cryogenic forging does not only increase the UTS of the alloys but also im- 
proves the ductility of the materials in comparison with the RTF processed samples. Nonequilibrium grain boundaries in UFG metals have also been recognized as a significant factor to improve ductility [31]. High density of dislocations is exposed to slip which enables grains to slide or rotate. As it is well known, the ductility of a material is highly dependent on their structural homogeneity. It can be concluded that homogeneous grain microstructure with low aspect ratio in CF samples was developed during cryogenic forging due to the multi axial process corresponding with recrystallization suppression as well as a high degree of grain refinement.

It is worth paying attention to the lowering effect of additional forging cycles on the elongation at fracture for both the CF and the RTF alloys as can be seen in the strain-strain curves in Figure 3(a). This stems from highly limited strain hardening that causes localized deformation in the processed samples with prolonged forging. The accumulate dislocations for strain hardening is almost infeasible due to the refined crystallite size and saturation of dislocations [32]. However, the decreasing rate of ductility in the RFT samples was observed to be higher than that of the CF samples such that this reduction between 4 and 6 cycles were $54 \%$ and $23 \%$ for the RTF and the CF samples, respectively.

The stress-strain response of the nanocrystalline CF alloys under tension shows a rapid peak and subsequent softening due largely to necking. The reason for this strength drop can be attributed to the intrinsic feature of nanoscale materials. The high surface (grain boundaries) to volume ratio of the nanograins may facilitate their rotation with a lower stress. Plastic deformation makes the nanosized grains to rotate and consequently coalesce along the directions of shear generating larger paths for dislocation movement. This phenomenon is schematically explained in Figure 4. The orientations of the slip systems are depicted by a short line in each grain in this figure. Beyond the peak of the stress-strain curves, plastic deformation aligned neighboring grains in the same

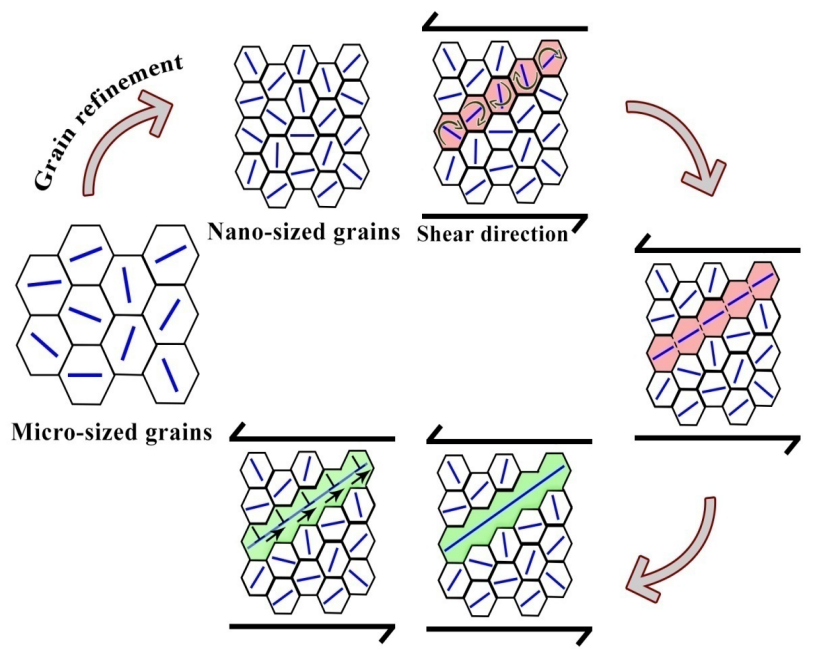

Figure 4. Schematics of rotation of the neighboring nanograins during plastic part of tensile test. 
orientation closer together. This may diminish their boundaries providing a path for more extended dislocation motion and may consequently lead to the softening behavior in the plastic zone [28].

The toughness per unit volume of the RTF and the CF materials was computed for various forging cycles using the integration method to obtain the areas of the true stress-strain curves and was depicted in Figure 3(b) for detailed evaluation with a comparative view. As seen, significantly higher amount of deformation energy has been absorbed in the CF materials during the tensile test in comparison with the conventionally forged samples. Hence, the samples made by cryogenic forging possess higher level of toughness which can be ascribed to their high density of dislocations and grain boundary sliding in such UFG structure [33].

\subsection{Fractography}

The deformation behavior of the materials was identified by the microstructural characterization of failure mechanisms at the tensile rupture surfaces and diagnosing failure modes using SEM. Fractographs of the materials subjected to tensile deformation are presented in Figure 5. Similar to the stress-strain profiles, the variation of the forging cycles from 2 to 6 was considered since they significantly affected the tensile behavior of the materials. In such materials the polished morphology that distinguishes brittle regions as well as the size and depth of micro-dimples is typically characterized to be an indication of ductile zones which nucleated from the $\mathrm{Al}_{2} \mathrm{Cu}$ second phase particles. Furthermore, each dimple is an evidence of a crack nucleation site, which has been linked up during the plastic deformation process. The fractured surface of the CF samples processed via 6, 4 and 2 forging were shown in Figure 5(a) and Figure 5(c) and Figure 5 (e) respectively. In the CF sample case, integration of mostly ductile domain

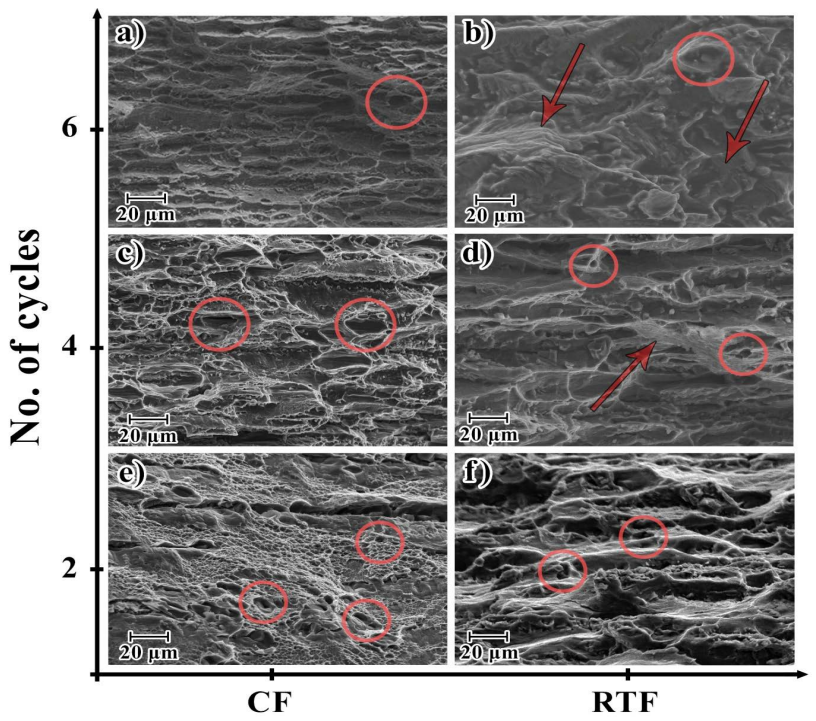

Figure 5. SEM fractographs after tensile test for (a) CF-6 Cycles; (b) RTF-6 Cycles; (c) CF-4 Cycles; (d) RTF-4 Cycles; (e) CF-2 Cycles and (f) RTF-2 Cycles samples. 
(marked with circles) and slight brittle fractured regions (showed with arrows) can be recognized while the small micro-dimples and polished morphology are visible on their fractured surfaces. Therefore, a typical ductile failure mode is present in the CF samples. However, less number of dimples with the reduced deep size is a clear proof of ductility reduction in the extended forging cycles which is in consistent with the stress-strain results. Rahmatabadi et al. [34] observed a similar increasing tensile strength and decreasing elongation by increasing the number of ARB cycles in the fractography of Aluminum.

On the other hand, a large area of polished morphology in Figure 5(b) imparts a brittle failure mode in RTF sample up to 6 forging cycles. This mode of rupture begins with microvoids formation and coalescence, crack growth and finally a shear fracture that leads to failure. Figure 5(d) and Figure 5(b) also show a considerable ductility reduction in the next cycles by a decrease in the number of deep dimples which can be attributed to highly stored internal strain while applying plastic deformation in the RTF samples.

The 6 cycle forged RTF samples have experienced a brittle fracture since no apparent plastic deformation took place as a result of tensile stress. Brittle fracture typically involves small energy absorption and occurs at high speeds. Also, a cleavage fracture surface is obvious on a part of this sample which is an indication of the brittle fracture caused by the normal stress to crystallographic planes with low bonding (cleavage planes). It is noted that conventional forging process makes fractured area with finer dimples which indicates lower ductility as compared to the CF materials with coarser and deeper dimples.

\section{Conclusions}

The following conclusions can be drawn from this study:

1) An integrated enhancement in mechanical strength, ductility and toughness of the AA2519 aluminum alloy was achieved as the result of cryogenic MAF process. This can be attributed to crystallite size refinement to nanoscales, heavily deformed grains with high density of grain boundaries and second phase breakage to finer particles observed through the XRD pattern and TEM micrographs of the cryogenic forging. Simultaneous SPD as well as the suppression of the dynamic recovery and recrystallization mechanisms during the cryogenic environment made the SPD process rather effective than performing the same process at room temperature.

2) The SEM micrographs of the fractured surfaces showed a significant ductility improvement in the CF materials which are in alignment with their stress-strain profiles. In addition, a slight increase in the tensile strength and a reduction in ductility are obtained in extended forging cycles due to less ability to accumulate dislocations. However, decreasing rate of ductility in the RFT samples was observed to be higher than that of the CF samples once proceeded to the next cycles.

Future study will focus on the effect of thermal treatments on the microstructure and mechanical response of the alloy after cryogenic forging in order to see 
the possibility of increasing the ductility of the processed alloy without any considerable strength loss.

\section{Acknowledgements}

Financial support for this work was provided through contract \# W911NF-151-0457 under the direct supervision of Patricia Huff (HBCU/MI Program Manager, ARO).

\section{Conflicts of Interest}

The authors declare no conflicts of interest regarding the publication of this paper.

\section{References}

[1] Monteiro, W.A., da Silva, S.L.V., da Silva, L.V., de Andrade, A.H.P. and da Silva, L.C.E. (2017) Characterization of Nickel Alloy 600 with Ultra-Fine Structure Processed by Severe Plastic Deformation Technique (SPD). Journal of Materials Science and Chemical Engineering, 5, 33-44. https://doi.org/10.4236/msce.2017.54004

[2] Zehetbauer, M.J. and Valiev, R.Z. (2006) Nanomaterials by Severe Plastic Deformation. John Wiley \& Sons, Hoboken.

[3] Berndt, N., Frint, P. and Wagner, M.F.-X. (2018) Influence of Extrusion Temperature on the Aging Behavior and Mechanical Properties of an AA6060 Aluminum Alloy. Metals, 8, 51. https://doi.org/10.3390/met8010051

[4] Fritsch, S. and Wagner, M.F.-X. (2018) On the Effect of Natural Aging Prior to Low Temperature ECAP of a High-Strength Aluminum Alloy. Metals, 8, 63. https://doi.org/10.3390/met8010063

[5] Nejadseyfi, O., Shokuhfar, A., Azimi, A. and Shamsborhan, M. (2015) Improving Homogeneity of Ultrafine-Grained/Nanostructured Materials Produced by ECAP Using a Bevel-Edge Punch. Journal of Materials Science, 50, 1513-1522. https://doi.org/10.1007/s10853-014-8712-3

[6] Khabushan, J.K. and Bonabi, S.B. (2017) Investigating of the Microstructure and Mechanical Properties of Al-Based Composite Reinforced with Nano-Trioxide Tungsten via Accumulative Roll Bonding Process. Open Journal of Metal, 7, 9-23. https://doi.org/10.4236/ojmetal.2017.71002

[7] Song, Y., Wang, W., Gao, D., Kim, H.-S., Yoon, E.-Y., Lee, D.-J., Lee, C.-S. and Guo, J. (2012) Inhomogeneous Hardness Distribution of High Pressure Torsion Processed IF Steel Disks. Materials Sciences and Applications, 3, 234-239. https://doi.org/10.4236/msa.2012.34034

[8] Chen, Q., Shu, D., Hu, C., Zhao, Z. and Yuan, B. (2012) Grain Refinement in an As-Cast AZ61 Magnesium Alloy Processed by Multi-Axial Forging under the Multitemperature Processing Procedure. Materials Science and Engineering: A, 541, 98-104. https://doi.org/10.1016/j.msea.2012.02.009

[9] Cherukuri, B. and Srinivasan, R. (2006) Properties of AA6061 Processed by Multi-Axial Compressions/Forging (MAC/F). Materials and Manufacturing Processes, 21, 519-525. https://doi.org/10.1080/10426910500471649

[10] Bruder, E. (2018) Mechanical Properties of ARMCO ${ }^{\circledR}$ Iron after Large and Severe Plastic Deformation-Application Potential for Precursors to Ultrafine Grained 
Microstructures. Metals, 8, 191. https://doi.org/10.3390/met8030191

[11] Panigrahi, S.K., Jayaganthan, R. and Chawla, V. (2008) Effect of Cryorolling on Microstructure of Al-Mg-Si Alloy. Materials Letters, 62, 2626-2629.

https://doi.org/10.1016/j.matlet.2008.01.003

[12] Magalhães, D.C.C., Kliauga, A.M., Ferrante, M. and Sordi, V.L. (2017) Plastic Deformation of FCC Alloys at Cryogenic Temperature: The Effect of Stacking-Fault Energy on Microstructure and Tensile Behaviour. Journal of Materials Science, 52, 7466-7478. https://doi.org/10.1007/s10853-017-0979-8

[13] Ahn, B. (2018) Synthesis and Properties of Bulk Nanostructured Metallic Materials. Metals, 8, 855. https://doi.org/10.3390/met8100855

[14] Nejadseyfi, O., Shokuhfar, A., Dabiri, A. and Azimi, A. (2015) Combining EqualChannel Angular Pressing and Heat Treatment to Obtain Enhanced Corrosion Resistance in 6061 Aluminum Alloy. Journal of Alloys and Compounds, 648, 912-918. https://doi.org/10.1016/j.jallcom.2015.05.177

[15] Longtin, R., Hack, E., Neuenschwander, J. and Janczak-Rusch, J. (2011) Benign Joining of Ultrafine Grained Aerospace Aluminum Alloys Using Nanotechnology. Advanced Materials, 23, 5812-5816. https://doi.org/10.1002/adma.201103275

[16] Suryanarayana, C. (1994) Structure and Properties of Nanocrystalline Materials. Bulletin of Materials Science, 17, 307-346. https://doi.org/10.1007/BF02745220

[17] Hansen, N. (2004) Hall-Petch Relation and Boundary Strengthening. Scripta Materialia, 51, 801-806. https://doi.org/10.1016/j.scriptamat.2004.06.002

[18] Ivanov, K.V. and Naydenkin, E.V. (2012) Grain Boundary Sliding in Ultrafine Grained Aluminum under Tension at Room Temperature. Scripta Materialia, 66, 511-514. https://doi.org/10.1016/j.scriptamat.2011.12.039

[19] Lee, Y.B., Shin, D.H., Park, K.-T. and Nam, W.J. (2004) Effect of Annealing Temperature on Microstructures and Mechanical Properties of a 5083 Al Alloy Deformed at Cryogenic Temperature. Scripta Materialia, 51, 355-359. https://doi.org/10.1016/j.scriptamat.2004.02.037

[20] Vendra, S.S.L., Goel, S., Kumar, N. and Jayaganthan, R. (2017) A Study on Fracture Toughness and Strain Rate Sensitivity of Severely Deformed Al 6063 Alloys Processed by Multiaxial Forging and Rolling at Cryogenic Temperature. Materials Science and Engineering: A, 686, 82-92. https://doi.org/10.1016/j.msea.2017.01.035

[21] Chen, Y.J., Roven, H.J., Gireesh, S.S., Skaret, P.C. and Hjelen, J. (2011) Quantitative Study of Grain Refinement in Al-Mg Alloy Processed by Equal Channel Angular Pressing at Cryogenic Temperature. Materials Letters, 65, 3472-3475. https://doi.org/10.1016/j.matlet.2011.07.067

[22] Azimi, A., Shokuhfar, A. and Zolriasatein, A. (2014) Nanostructured Al-Zn-Mg-Cu-Zr Alloy Prepared by Mechanical Alloying Followed by Hot Pressing. Materials Science and Engineering: A, 595, 124-130. https://doi.org/10.1016/j.msea.2013.11.094

[23] Azimi, A., Fallahdoost, H. and Nejadseyfi, O. (2015) Microstructure, Mechanical and Tribological Behavior of Hot-Pressed Mechanically Alloyed Al-Zn-Mg-Cu Powders. Materials \& Design, 75, 1-8. https://doi.org/10.1016/j.matdes.2015.03.011

[24] Tan, E., Kibar, A.A. and Gür, C.H. (2011) Mechanical and Microstructural Characterization of 6061 Aluminum Alloy Strips Severely Deformed by Dissimilar Channel Angular Pressing. Materials Characterization, 62, 391-397. https://doi.org/10.1016/j.matchar.2011.01.016

[25] Adamczyk-Cieslak, B., Zdunek, J. and Mizera, J. (2016) Evolution of Microstructure and Precipitates in 2xxx Aluminum Alloy after Severe Plastic Deformation. IOP 
Conference Series. Materials Science and Engineering, 123, 1-4. https://doi.org/10.1088/1757-899X/123/1/012019

[26] Azadmanjiri, J., Berndt, C.C., Kapoor, A. and Wen, C. (2015) Development of Surface Nano-Crystallization in Alloys by Surface Mechanical Attrition Treatment (SMAT). Critical Reviews in Solid State and Materials Sciences, 40, 164-181. https://doi.org/10.1080/10408436.2014.978446

[27] Zuiko, I. and Kaibyshev, R. (2017) Deformation Structures and Strengthening Mechanisms in an Al-Cu Alloy Subjected to Extensive Cold Rolling. Materials Science and Engineering: A, 702, 53-64. https://doi.org/10.1016/j.msea.2017.07.001

[28] Meyers, M.A., Mishra, A. and Benson, D.J. (2006) Mechanical Properties of Nanocrystalline Materials. Progress in Materials Science, 51, 427-556. https://doi.org/10.1016/j.pmatsci.2005.08.003

[29] Pavlina, E.J. and Van Tyne, C.J. (2008) Correlation of Yield Strength and Tensile Strength with Hardness for Steels. Journal of Materials Engineering and Performance, 17, 888-893. https://doi.org/10.1007/s11665-008-9225-5

[30] Queyreau, S., Monnet, G. and Devincre, B. (2010) Orowan Strengthening and Forest Hardening Superposition Examined by Dislocation Dynamics Simulations. Acta Materialia, 58, 5586-5595. https://doi.org/10.1016/j.actamat.2010.06.028

[31] Valiev, R.Z., Alexandrov, I.V., Zhu, Y.T. and Lowe, T.C. (2002) Paradox of Strength and Ductility in Metals Processed Bysevere Plastic Deformation. Journal of Materials Research, 17, 5-8. https://doi.org/10.1557/JMR.2002.0002

[32] Gong, Y.L., Wen, C.E., Li, Y.C., Wu, X.X., Cheng, L.P., Han, X.C. and Zhu, X.K. (2013) Simultaneously Enhanced Strength and Ductility of $\mathrm{Cu}-\mathrm{xGe}$ Alloys through Manipulating the Stacking Fault Energy (SFE). Materials Science and Engineering: $A$, 569, 144-149. https://doi.org/10.1016/j.msea.2013.01.022

[33] Das, P., Jayaganthan, R. and Singh, I.V. (2011) Tensile and Impact-Toughness Behaviour of Cryorolled Al 7075 Alloy. Materials \& Design, 32, 1298-1305. https://doi.org/10.1016/j.matdes.2010.09.026

[34] Rahmatabadi, D., Hashemi, R., Mohammadi, B. and Shojaee, T. (2017) Experimental Evaluation of the Plane Stress Fracture Toughness for Ultra-Fine Grained Aluminum Specimens Prepared by Accumulative Roll Bonding Process. Materials Science and Engineering: A, 708, 301-310. https://doi.org/10.1016/j.msea.2017.09.085 